\title{
OUTCOMES OF SURGICAL TREATMENT OF LOWER-LIMB CHRONIC VENOUS INSUFFICIENCY
}

Van Minh Tri*, Nguyen Hoai Nam*

\section{ABSTRACT}

From 08/2004-08/2006, there were 157 patients diagnosed with lower-extremity CVI undergoing surgery at Medicine and Pharmacy Hospital. There were more females than males $(2.2 / 1)$ and the disease was occupation-related. Indications for surgery was CVI of grade II or higher. Stripping surgery in isolation or in combination with Muller procedure was highly effective and provided good cosmetic results. Surgical treatment of lower-limb CVI was associated with low risk of complications, good outcomes and high satisfaction of patients. Surgery should be indicated for patients with grade II or higher CVI.

\section{INTRODUCTION:}

Lower-extremity chronic venous insufficiency (CVI) is related to the reflux and the insufficient return flow inside the veins. Although the disease usually does not result in death but with time, it will affect the work, daily activities and the quality of life of the patients.

This disease is common in developed countries and significantly associated with lifestyle. In the United States, more than 20 millions of patients are affected by this disease. In Japan, $45 \%$ of workers suffer from lower-limb CVI.

The economic development in our country has improved people's life but at the same time, the prevalence of lower-limb CVI is also increasing and more people are paying attention to this disease. The need for treatment is raising, but there is no consensus regarding the best therapy between internal-medicine doctors and surgeons. Accordingly, we conducted this study to evaluate the outcomes of surgical treatment of lowerextremity CVI at Medicine and Pharmacy Hospital in order to draw conclusions about indications, surgical techniques and risk factors of the disease.

\section{SUBJECTS AND STUDY METHODS:}

This is a retrospective observational study of 157 patients diagnosed with lower-extremity CVI that underwent surgical treatment at Department of Thoracic and Vascular Surgery, Medicine and Pharmacy Hospital from 08/2004 to 08/2006.

\section{RESULTS:}

Of 157 lower-limb CVI cases undergoing surgery from August 2004 to August 2006 at Department of Thoracic and Vascular Surgery, Medicine and Pharmacy Hospital, 109 patients were females (49 males), corresponding to a female: male ratio of 2.2/1. The mean age of study subjects was 52.8 years old (range: $23-80$ years old). A total of 54 patients suffered from the disease in both legs, accounting for $34.4 \%$. Most patients $(n=103$, $65.6 \%$ ) had only one extremity affected.

*University of medicine and pharmacy at HCM city Scientific director: A/ Prof.|Nguyen Hoai Nam, PhD Manuscript received: 01/02/2019-Accepted for publication: 23/03/2020 Scientific reviewer: A/ Prof. Dang Ngoc Hung, PhD Prof. Le Ngoc Thanh, PhD 


\section{Occupation:}

\begin{tabular}{lcc}
\hline \multicolumn{1}{c}{ Occupation } & Number of patients & Percentage $\%$ \\
\hline Teacher & 33 & $21.1 \%$ \\
Shop assistant & 38 & $24.2 \%$ \\
Tailor & 17 & $10.8 \%$ \\
Farmer & 47 & $29.9 \%$ \\
Office worker & 14 & $8.9 \%$ \\
Other & 8 & $5.1 \%$ \\
\hline
\end{tabular}

Most patients had occupations that require prolonged standing or sitting $(86 \%)$.

Time from disease onset to surgery:

\begin{tabular}{lcc}
\hline & Time & Number of patients $(\%)$ \\
\hline$<5$ years & $38(24.2 \%)$ \\
$5-10$ years & $43(27.4 \%)$ \\
$>10$ years & $76(48.4 \%)$ \\
\hline
\end{tabular}

Most patients had the disease for at least 5 years before surgery.

\section{Clinical symptoms:}

\begin{tabular}{lcc}
\hline \multicolumn{1}{c}{ Symptoms } & Number of patients & Percentage \\
\hline Varicose vein & 157 & $100 \%$ \\
Pedal oedema, heavy legs & 123 & $65.6 \%$ \\
Cramp & 44 & $28.0 \%$ \\
Darken skin & 31 & $19.8 \%$ \\
Numbness & 27 & $17.2 \%$ \\
Venous ulcer & 20 & $12.7 \%$ \\
\hline
\end{tabular}

\section{Clinical classification according to CEAP}

\begin{tabular}{ccc}
\hline CEAP & Number of patients & Percentage \\
\hline 2 & 25 & $15.9 \%$ \\
3 & 81 & $51.6 \%$ \\
4 & 31 & $19.8 \%$ \\
5 & 20 & $12.7 \%$ \\
\hline
\end{tabular}

We only classified patients based on clinical findings. Aetiology, anatomy and physiopathology were not considered. We classified until the highest grade and found that most patient had grade 2 and 3 disease $(67.5 \%)$.

\section{Para-clinical findings:}

\begin{tabular}{lc}
\hline \multicolumn{1}{c}{ Doppler ultrasound } & Number of patients \\
\hline Varicose vein & $157(100 \%)$ \\
Deep venous incompetence & $128(81.5 \%)$ \\
\hline
\end{tabular}




\section{Surgical methods:}

\begin{tabular}{lc}
\hline \multicolumn{1}{c}{ Surgical method } & Number of surgeries \\
\hline Muller & 4 \\
Stripping & 66 \\
Stripping + Muller & 141 \\
\hline
\end{tabular}

We performed stripping surgery to remove the great saphenous vein through skin incisions at the groin and ankle in combination with Muller surgery to remove local varicose veins. Isolated Muller surgery was performed in 4 patients only as the varicose vein lied on the way of small saphenous vein.

\section{Complications and outcomes:}

\begin{tabular}{lcc}
\hline \multicolumn{1}{c}{ Outcomes - Complications } & Number of cases & Percentage \\
\hline Improved symptom of heavy leg & 119 & $75.8 \%$ \\
Pain and bruise along the removed vein & 31 & $19.7 \%$ \\
Saphenous nerve injury & 11 & $7.0 \%$ \\
Groin haematoma & 1 & \\
Deep vein thrombosis & 0 & \\
Death & 0 & \\
\hline
\end{tabular}

\section{CONCLUSIONS:}

\subsection{Aetiology and risk factors:}

According to G.Fowkes, professor of epidemiology (United Kingdom) 2001: lowerextremity CVI is common with a third of Western population suffering from the disease. The prevalence of the disease increases with age and can be related to demographic factors. Prolonged standing is one of the risk factors.

Furthermore, obesity and prior pregnancy are usually associated with varicose veins but these relationships are not consistent. Jari O Laurikka, Finland, in a study about the epidemiology of this disease showed that the male/female ratio was $1 / 3$, the risk factors for developing the disease was female gender, the number of pregnancies, family history, advanced age, and finally, occupations that require prolonged standing. The prolonged standing weakens the muscular pump assisting the return of venous blood and results in blood retention [2]. In our study, CVI was also more common in women than men (women/men ration was 2.2/1) and most of patients $(86 \%)$ had occupations that require standing for a long period of time.

\subsection{Clinical classification:}

In 1994, a group of international experts introduced the CEAP classification system of lower-limb venous disease which was rapidly adopted worldwide. CEAP classification is considered the most optimal system as it considers all main aspects of lower-limb venous diseases such as clinical findings, aetiology, anatomy, and physiopathology, etc [5].

In our study cohort, patients were also classified based on CEAP system. However, not all aspects were evaluated, only clinical findings were used to classify patients with grade 2 and 3 accounting for $67.5 \%$ in total.

Doppler ultrasound is a simple, effective and safe diagnostic tool that could be used to investigate venous diseases. Contrast-enhanced venous imaging is more effective than Doppler ultrasound in differentiating primary and secondary causes but this technique is difficult to perform and can even lead to death due to contrast-induced shock [5]. 
In our study, we only used Dopple ultrasound to examine the venous system and in all cases, pathological findings were found.

\subsection{Surgical indications and techniques:}

The goal of surgery is to make sure that all varicose veins that cause increased venous pressure are removed completely with highest cosmetic outcome possible and minimal complication rate [3].

J. Ciucci 1999[1] in his study about lowerextremity venous diseases performed surgery for only patients with CVI of CEAP grade 3 or higher and the techniques were saphenofemoral vein disconnection (100\%), stripping of internal saphenous vein $(88 \%)$ with or without removal of external saphenous vein, and Muller surgery $(2.9 \%)$.

According Khirurgiia 2002 [4], to treat lowerlimb venous diseases, sapheno-femoral disconnection, stripping of great saphenous vein and segmental removal of varicosities (Muller surgery) are simple, have low complication rates and high cosmetic value.

We planned to use surgical treatment for patients with CVI of grade 2 or higher, i.e. having varicose vein on physical examination. The method of choice was Stripping (to remove the great saphenous vein) with small skin incisions at the groin and ankle. Local varicose veins were removed by local short skin incisions (Muller surgery).

With these methods, almost all varicose veins were removed with short skin incisions which have high cosmetic value. After surgery, all patients had their legs bandaged to stop bleeding.

\subsection{Early outcomes of surgical treatment:}

According to J.Ciucci [1], postoperative complications included: nerve injury: $0 \%$, haematoma along the course of the varicose vein: $13 \%$, infection: $1.7 \%$. In our study, nerve injury occurred in $7 \%$ of patients and bruises along the course of removed vein accounted for $19.7 \%$ of patients, $>70 \%$ of patients had good outcomes.

As our patients had long disease duration, there were many varicose veins and we had to perform many Muller surgeries, which could explain the high frequencies of pain and bruises along the course of the removed veins.

\section{CONCLUSIONS:}

In a study of 157 patients with lower-limb CVI that underwent surgery at Department of Thoracic and Vascular Surgery, Medicine and Pharmacy Hospital from 08/2004 to 08/2006, we found that:

- CVI is more prevalent in women than men and is associated with occupations that require prolonged standing.

- Indications for surgery was having varicose vein on clinical examination (grade 2 or higher).

- Stripping surgery in combination with Muller surgery when necessary was effective with low complication rate.

\section{REFERENCES}

1. Ciucci J. (1999). Quality control in varicose vein surgery: significance and feasibility.

2. Jari. O. Laurikka. Risk indications for varicose veins in forty to sixty Y.O in the tempere varicose vein study. World Journal of Surgery. June 2002, V. 26, N. 6. p 648.

3. John j. Bergan. Varicose veins: treatment by surgery and sclerotherapy. Vascular Surgery, vol. 2, 2000, p. 2007-2021.

4. Khirurgiia (Mosk). Surgical Technologies in the treatment of lower extremity varicose disease. (1): 10-5 Related Articles, Book, 2002.

5. Robert L. Kistner, Elna M. Masuda. A practical approach to the diagnosis and classification of chronic venous disease. Vascular Surgery, vol. 2, 2000, p. 1990-1999. 